\title{
Теоретичні аспекти фрілологічних досліджень
}

УДК 81'1:165.194

DOI: $10.26565 / 2227-1864-2019-82-16$

\section{О наличии родовых понятий при отсутствии их названий (на примере языка пирахан)}

\author{
C. Л. Попов \\ доктор филологических наук, профессор кафедры русского языка, \\ Университет имени Сунь Ятсена (Гуанчжоу, Китай); \\ e-mail: s.leon.popov@gmail.com; https://orcid.org/0000-0002-3257-6245
}

Ряд лингвистов считают, что у носителей языков, которые считаются первобытными и в которых отсутствуют номинации родовых понятий, эти понятия имеются. В статье предпринимается попытка проверить теоретическую обоснованность утверждения о наличии родовых понятий в сознании при отсутствии их номинаций в языке и выявить причину такого утверждения. Выдвигается гипотеза, что признание наличия родовых понятий в сознании при отсутствии их номинаций в языке представляет собой такую распространенную в наше время логическую ошибку, как подмена понятия, которая в данном случае состоит в перенесении современной ментальности на ментальность первобытного человека. На материале языков активного строя, в которых имеется лишь одна обобщенная оппозиция «живое - неживое», к которым относится рассматриваемый в статье язык пирахан и в которых из-за преобладания синкретизма восприятия невозможно обобщение по более частным признакам, чем признаки живого и неживого, на примерах корреляций структурных характеристик языка пирахан с характеризующейся отсутствием прилагательных и обобщенных существительных речью полуторагодовалых, но не двухлетних цивилизованных детей, на примерах обобщенности-необобщенности цветообозначений в цивилизованных и первобытных, в том числе пирахан, языках, с применением понятий объема памяти, степеней восприятия, логики как строя мышления и тесно связанной с обобщением абстрактности мышления доказывается, что постулируемое только для первобытных языков наличие родовых понятий при отсутствии их обозначений невозможно, а утверждение данного наличия является такой распространенной в настоящее время подменой понятия, как перенесение современной цивилизованной ментальности на ментальность первобытную.

Ключевые слова: пирахан, выражение родовых понятий, обобщение, память, восприятие, логика, абстрактное мышление

Попов С. Л. Про наявність родових понять при відсутності їх назв (на прикладі мови пірахан)

Ряд лінгвістів вважають, що у носіїв мов, які вважаються первісними і в яких відсутні номінації родових понять, ці поняття $€$. У статті робиться спроба перевірити теоретичну обюрунтованість твердження про наявність родових понять у свідомості за відсутності їх номінацій у мові та виявити причину такого твердження. Висувається гіпотеза, що визнання наявності родових понять у свідомості за відсутності їх номінацій у мові становить таку поширену в наш час логічну помилку, як підміна поняття, яка в даному випадку полягає у перенесенні сучасної ментальності на ментальність первісної людини. На матеріалі мов активного ладу, в яких наявна лише одна узагальнена опозиція "живе - неживе", до яких відноситься розглянута у статті мова пірахан і в яких через переважання синкретизму сприйняття $є$ неможливим узагальнення за більш приватним ознаками, ніж ознаки живого і неживого, на прикладах кореляцій структурних характеристик мови пірахан з таким, що характеризується відсутністю прикметників і узагальнених іменників, мовленням півторарічних, але не дворічних цивілізованих дітей, на прикладах узагальненості-неузагальненості позначень кольорів у цивілізованих і первісних, в тому числі пірахан, мовах, із застосуванням понять обсягу пам'яті, ступенів сприйняття, логіки як ладу мислення і тісно пов'язаної з узагальненням абстрактності мислення підтверджується, що, така, що постулюється тільки для первісних мов, наявність родових понять за відсутності їх позначень $€$ неможливою, а твердження цієї наявності $є$ такою поширеною під сучасну пору підміною поняття, як перенесення сучасної цивілізованої ментальності на ментальність первісну.

Ключові слова: пірахан, вираз родових понять, узагальнення, пам'ять, сприйняття, логіка, абстрактне мислення

Popov Sergei. On the availability of generic concepts in the context of their non-available naming units (in terms of the Pirahã language)

Certain linguists believe that speakers of the mother-tongues which are considered to be primitive without any nomination of generic concept have such concepts. The paper is aimed at testing the theoretical substantiation of the statement concerning the available generic concepts in the consciousness in terms of the non-availability of their nomination in the language and specifying the reason of such a statement. A hypothesis is made on the fact that the acceptance of the availability of generic concepts in the consciousness in terms of their non-available nominations in the language is such a wide logical error as substitution of notions meaning the transference of the modern mentality onto the mentality of a primitive man.

Analyzing the material of active-structure languages which have only one generalized "living - nonliving" opposition (which includes the Pirahã language considered in the paper) and which are impossible to generalize in terms of more specific features than living and nonliving signs (due to the prevailing syncretism), in terms of the correlations of structural characteristics of the Pirahã language with the peculiar non-availability of adjectives and generalized nouns in the language of half-year-old (but not two-yearold) children, in terms of the generalization/non-generalization of colour nomination in the civilized and primitive (including Pirahã) languages, applying the notion of memory, degrees of perception, logics as thinking structure, and abstract nature of thinking (closely connected with the generalization), it is proved that the availability of generic concepts in terms of the non-availability of their definitions (postulated only for the primitive languages) is impossible; and confirmation of that availability is such a substitution of notions today as the transference of the modern civilized mentality onto the primitive mentality. Key words: Pirahã, expression of generic concepts, generalization, memory, perception, logics, abstract thinking 
Ряд лингвистов полагают, что у носителей языков, которые принято называть первобытными и в которых отсутствуют номинации родовых понятий, эти понятия имеются. Например, эти лингвисты убеждены в том, что в сознании таких носителей имеется обобщенное понятие «дерево», хотя обозначающая ее номинация в их языке отсутствует - в нем присутствуют лишь видовые названия деревьев, однако при необходимости выразить ментальное обобщение «дерево» такие носители употребляют название наиболее распространенного вида дерева. В частности, в этом убежден создатель эволюционносинтетической языковой теории А. Д. Кошелев, оперирующий достаточно свежими сведениями об относительно недавно описанном Д. Л. Эвереттом [13] амазонском языке пирахан. «Мы считаем, что значение родового имени типа дерево (= концепт ДЕРЕВО) входит универсальным компонентом в значения видовых имен дуб, береза, сосна и др., дополняясь в каждом случае соответствующими более конкретными характеристиками, - не очень новаторски и вполне бесспорно начинает А. Д. Кошелев. «И в этом плане концепт ДЕРЕВО универсален. При переводе сенсорных предложений типа Человек лезет на дерево / пилит дерево / поливает дерево на такие языки слово дерево заменяется именем наиболее распространенного вида дерева без искажения значения исходного предложения» - здесь автор отклоняется в сторону признания несущественности отсутствия родовой номинации и в сторону возможности бесхитростной компенсации такого отсутствия, после чего, увеличивая угол отклонения, переходит к главному и, что важно, не терпящему возражений (об этом свидетельствует сочетание вовсе не означает) и никак не обоснованному выводу: «Кроме того, отсутствие в языке родового имени типа дерево вовсе не означает отсутствия соответствующего родового понятия (концепта ДЕРЕВО)» [7, с. 32].

Целью настоящей статьи являются проверка теоретической обоснованности утверждения о наличии родовых понятий в сознании при отсутствии их номинаций в языке и выявление причины такого утверждения.

Прежде всего приходится заметить, что соображение об употреблении наиболее распространенного видового названия в качестве родового представляется не более доказательным, чем более общее утверждение о наличии родовых понятий при отсутствии их названий, поскольку и в первом, и во втором случаях какие-либо - эмпирически верифицированные или хоть каким-то образом обоснованные теоретические - доказательства отсутствуют. Не приходится сомневаться в том, что эмпирическая верификация в данном случае невозможна: ни одной эмпирической структуре человека не под силу приникнуть в сознание носителя первобытного языка с целью понять, в

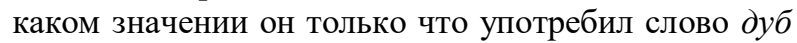
- обобщенном или частном, И этот носитель вряд ли поможет исследователю это понять, потому что понятие «дерево» одного денотата не имеет, слова любой в этом языке нет, и единственное, что носитель может предпринять для доказательства обобщенности значения слова дуб, - это энергичное перемещение от дуба к березе, от березы к клену, от клена к вязу с указанием на эти деревья и

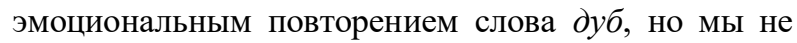
уверены ни в том, что носитель такое действие предпримет, ни в том, что он будет правильно понят исследователем, в частности будет им воспринят как психически адекватный коммуникант. Здесь уместно вспомнить, что десятилетиями ранее, а именно во время Второй мировой войны, было распространено явление, когда немцы называли русских солдат иванами, а русские назвали немецких солдат гансами, но это делалось намеренно, насмешливо, презрительно и с издевкой, чтобы показать, что все русские или немцы для говорящего одинаковы, а не потому, что в немецком и русском языках не было обобщенных названий их носителей.

Поскольку, как можно видеть, признание наличия родовых понятий при отсутствии их номинаций выглядит достаточно натянутым и, как следствие, малоубедительным, в первую очередь возникает предположение, что признание наличия родовых понятий в сознании при отсутствии их номинаций в языке представляет собой такую довольно распространенную в наше время логическую ошибку, как подмена понятия, которая в данном случае заключается в перенесении современной ментальности на ментальность первобытного человека.

Простым силлогистическим путем несложно прийти к выводу, что родовые слова как обобщающие номинации нужны в одном случае: чтобы противопоставить соответствующий, названный такой обобщающей номинацией род другому роду, тоже названному другой обобщающей номинацией, например противопоставить род человека родам зверей, птиц и рыб. Понятно, что, если потребность в таком противопоставлении отсутствует, эти роды не различаются, то есть люди, звери, птицы и рыбы не различаются по соответствующим родам и интегрируются, причем вместе с номинациями видов и растительного мира, по признаку «живое» (все, в чем присутствует жизненный цикл), который на лексическом и грамматическом уровнях противопоставляется признаку «неживое». И здесь очень важно обратить внимание на то, что противопоставление живого и неживого, или, в принятой терминологии, активного и инактивного, свойственно всем языкам с активным строем [6, с. 4 , 
53-77], например праиндоевропейскому [2, с. 267-319], некоторым другим семьям и языкам в той или иной мере, но, что особенно важно для цели настоящей статьи, ряду хорошо изученных североамериканских индейских языков, например языков выделенной в свое время Э. Сепиром большой семьи на-дене (северозапад Канады и Аляска), а также таких языков сиу, как ассинибойн (носители - кочевники) и понка (носители - уже оседлые охотники на бизонов) (центральный регион США), и мускоги, или галф (юг и юго-восток США), и ряду плохо изученных индейских языков Южной Америки, например многим языкам семьи тупи-гуарани [5, c. 80-81, 231, 246] и языкам бассейна Амазонки, к которым и принадлежит рассматриваемый Д. Л. Эвереттом и А. Д. Кошелевым язык пирахан. Остальные (сравнительно немногие) америндские языки в основном имеют следующий на эволюционной лестнице языковых строев строй эргативный, но со значительными остатками в их структурах строя активного [5, с. 246]. Благодаря этим данным можно с большой долей уверенности предположить, что язык пирахан тоже относится к языкам активного строя. Однако наблюдения над этим языком, произведенные Д. Л. Эвереттом [13], теперь уже бывшим миссионером и с момента начала жизни с индейцами пирахан лингвистом-любителем, и тщательно описанные А. Д. Кошелевым, формируют нашу убежденность в том, что пирахан - язык активного строя.

В пирахан нет грамматических категорий рода, падежа, числа, времени и залога, лексических показателей времени, числительных и счетных слов [13; 7, с. 439], и, поскольку индеец пирахан не может сказать чай сладкий, а прибегает к синкретичному сравнительному аналогу чай как мед [Кошелев, c. 442], мы можем сделать вывод и об отсутствии в пирахан прилагательных. Эти же категории, слова и части речи, как во всех подробностях продемонстрировал А. Г. Климов, отсутствуют в языках именно активного строя [6, с. 105-107, 144-146, 156-157]. Это далеко не все описанные непрофессионалом Д. Л. Эвереттом особенности активного строя, сменяющего строй классный (сейчас такой переход наблюдается среди нигероконголезских языков в языках банту [6, с. 281287]) и предшествующего строю эргативному или непосредственно номинативному (эргативизация активного строя наблюдается в таких языках, как баскский, абхазско-адыгские, нахско-дагестанские, бурушаски, папуасские, австралийские, чукотско-камчатские, эскимосско-алеутские, алгонкинские, чинукцимшиан, юто-ацтек, пано-такана, салиш и других, а минующая эргативный строй номинативизация активного строя наблюдается в индоевропейских, картвельских, енисейских, кечумара (кечуа и аймара), афразийских и некоторых других [6, с. 287, 292]). Но для доказательства принадлежности пирахан к языкам активного строя замеченных Д. Л. Эвереттом и пересказанных А. Д. Кошелевым особенностей вполне достаточно.

Получается, что А. Д. Кошелев, постулируя диахронический подход [7, с. 10] и на протяжении всего текста монографии уделяя много внимания диахронии детской речи - онтогенезу с постулированием корреляции между отногенезом и антропогенезом, игнорирует диахронию языкового развития, отраженную в контенсиологической типологии А. Г. Климова. Однако именно указанная типология позволяет понять, что носители языков активного строя, различая лишь живое и неживое, не вдаваясь на этом уровне их когнитивного развития в более тонкие различия живого и неживого, в своих обобщениях не продвигаются дальше объединений двух групп, полученных в результате весьма элементарного деления всех отраженных в языке явлений действительности по простейшему в ходе человеческого познания бинарному - принципу (о предшествовании принципа бинарности всем остальным видам дифференциации явлений действительности в ходе их познания - см. [4, с. 84-108]). Поэтому нет никаких оснований приписывать носителям языков активного строя понимание более частных обобщенных признаков, в данном случае понятийно родовых, которые они пока не различают, демонстрируя в данном случае типичный когнитивный синкретизм, о котором пишет и сам А. Д. Кошелев: «...в развитии индейцев какие-то их ментальные представления действительности всё еще остаются синкретичными, недифференцированными» [7, с, 441]. Какое обобщенное понятие дерева, животного, горы, моря и т. д. может сформироваться при наблюдаемом у носителей языков активного строя синкретизме восприятия, когда никакие, в том числе позволяющие делать обобщения интегральные, признаки, кроме признака «живое - неживое», еще не выделяются, - вопрос, по всей видимости, риторический.

Ссылаясь на ряд современных исследований развития детского мышления, А. Д. Кошелев отмечает, что «с середины первого года жизни младенец начинает различать неживые объекты и живые существа. Он уже понимает, что, в отличие от людей и животных, физические предметы не способны к самодвижению (например, начать движение без внешнего воздействия другого предмета, резко остановиться в отсутствии [конечно, в отсутствие. - С. П.] препятствия) и не могут двигаться целенаправленно: огибать препятствия, останавливаться перед ним и возвращаться назад и т. п.» [7, с, 17]. Именно с этим уровнем когнитивного развития ребенка, уровнем, на котором он различает лишь живое и неживое, и сопоставимы приводимые А. Д. Кошелевым ниже (см. [7, с, 32]) примеры отсутствия родовых слов «в 
некоторых языках», а именно в упоминаемых им со ссылками на других авторов австралийских и тех америндских языках, которые как раз и являются языками активного строя.

А. Д. Кошелев пишет о том, что в конце второго года жизни в речи ребенка появляются слова, значимые не предметно, а функционально, например прилагательные грязный и нахальный [7, с. 25-26]. А. Н. Гвоздев тоже отмечал, что в речи его сына Жени прилагательные, прежде всего качественные, начали массово появляться лишь с двухлетнего возраста [3, с. 21-24]. Очевидно, что появление в речи ребенка прилагательных знаменует собой начало процесса дифференциации ранее синкретично воспринимаемых сущностей путем вычленения различных их признаков. Понятно, что начало этого процесса обусловливает и начало процесса интеграции дифференцируемых сущностей по совпадающим, то есть интегральным, полученным в результате предшествующей дифференциации признакам, что успешно приводит к потребности противопоставления и соответствующего номинирования полученных в результате интеграции родов, например родов более частных, чем все живое. И здесь очень важно понимать, что отсутствие этого адъективного процесса в полуторагодовалом возрасте ребенка абсолютно идентично упомянутому выше отсутствию прилагательных в языках активного строя, живому классу которых, таким образом, нелогично приписывать более частные родовые понятия, чем понятия живого и неживого, поскольку отсутствие в языке ребенка или этноса прилагательных означает следующее из синкретичного невычленения при этом интегральных и дифференциальных признаков предметов отсутствие способного к разнообразным обобщениям абстрактного мышления. А. Г. Климов замечает, что в позднеактивном строе прилагательные начинают появляться от стативных (непереходных) глаголов по типу Дом белеет Дом бельій [6, с. 105-107]. В таком случае ясно, что и признаковая оппозиция «живое - не живое» происходит от глагольной оппозиции «живет - не живет», и важно понимать, что указанная признаковая оппозиция в среднестатистических языках активного строя единственная, и пирахан является именно таким языком.

А. Д. Кошелеву было бы уместно ситуацию наличия-отсутствия родовых понятий у носителей языков активного строя соотнести с тем, что он пишет о тоже двухлетних детях: «Например, видя, как окружающие называют словом ножка такие внешне разные части предметов, как ножка стула, ножка дивана, ножка торшера и под., ребенок понимает, что все эти части объединяет их функция 'удерживать предмет над землей от падения на нее’» [7, с. 30]. Нельзя не согласиться с тем, что ребенок достаточно быстро понимает, что ножкой называется любой предмет, который удерживает предмет над землей от падения на нее, но важно сознавать, что он понимает это, постоянно пребывая в преимущественно взрослом цивилизованном человеческом социуме, в то время как первобытные люди, в нашем случае носители языков активного строя, постоянно пребывают в среде себе подобных, когнитивный уровень которых одинаков независимо от возраста. В этом смысле показателен рассказ известного исследователя детского интеллекта М. Мид. Ее интересовал вопрос: если мышление первобытных взрослых аналогично мышлению цивилизованных детей, то чем мышление первобытных детей отличается от мышления первобытных взрослых? Чтобы найти ответ, М. Мид собрала 35000 рисунков, выполненных первобытными детьми, и «обнаружила вопреки всем ожиданиям, что «примитивные дети» не проявляют ни малейшего следа естественного анимизма наших детей, рисующих на луне человека, а дома с лицами» $[9$, с. 35]. Рисунки этих детей не отличались от рисунков первобытных взрослых: они были натуралистичными. Через 25 лет М. Мид, специально вернувшись в это место, попросила тех же (уже бывших) детей порисовать и обнаружила, что их рисунки были в точности такими же, как четверть века назад [9, с. 37].

Как показывают многочисленные исследования первобытных языков, их носители, обладая сравнительно небольшим запасом знаний и как следствие не имея в языке значительного количества не только слов, но зачастую и звуков по причине отсутствия в них номинативной и коммуникативной потребностей, то есть имея достаточный объем свободной памяти, при уже описанном выше отсутствии обобщений «частнее» живого и неживого склонны каждому новому предмету давать отдельную номинацию. Достаточно вспомнить широко известное многообразие названий снега в чукотском языке при отсутствии соответствующего родового понятия. Но когнитивная эволюция возможна: ранее в эскимосском языке не было родового названия тюленя, но уже более ста лет это название имеется, и оно не является названием самого распространенного вида тюленей, поскольку эскимосы имеют дело только с одним видом тюленей [1, с. 171-172]. Поэтому можно вполне гарантированно предположить, что, если носитель языка активного строя познает такие сущности, как ножки стула, ножки дивана и ножка торшера, он даст этим ножкам отдельные названия, и это еще раз докажет как некорректность мнения об обобщающих понятиях у носителей таких языков, так и необходимость изучать контенсиологическую типологию языков, разработке которой посвятил свою жизнь выдающийся лингвист А. Г. Климов. 
В развитых языках обобщенные номинации возможны для различных названий цвета, но в языках активного строя такое обобщение невозможно. Комментируя цветообозначения в пирахан, А. Д. Кошелев считает, что отсутствие в пирахан традиционных цветообозначений обусловлено синкретичной невозможностью расчленить цвета спектра на составляющие (чего, собственно говоря, не может сделать и современный цивилизованный человек без трехгранной призмы, впервые примененной для этой цели Ньютоном), а отсутствующее у них разнообразие видов деятельности является причиной отсутствия спектральных цветообозначений [7, с. 444-447]. Автор верно говорит о синкретизме восприятия его носителей, но совершенно упускает из виду, что важнейшим признаком синкретизма является отсутствие абстрактного мышления и, как следствие, способности к обобщению. Помнить об этом признаке синкретизма важно потому, что существующие в непервобытных языках цветообозначения являются именно обобщениями, а в первобытных языках - все наоборот, чему посвящена обширная литература. Например, А. Р. Лурия во время экспедиции в труднодоступные районы Средней Азии в речи людей, живших традиционной (не колхозной) жизнью, обнаружил следующие - совершенно частные, привязанные к предметам, а не обобщенные - цветообозначения: ириса, граната, персика, фисташки, табака, печени, вина, кирпича, испорченного хлопка, леденца, розы, телячьего помета, помета свиньи, гороха, озера, неба, мака, темного сахара, испорченньх зубов, иветущего хлопка, воды, когда ее много, и др. [8, с. 38-39].

Когда А. Д. Кошелев считает, что в пирахан нет цветообозначений, он, конечно, говорит об обобщенных цветообозначениях типа красный, бельій, желтый и т. п. Затем автор приводит примеры Д. Л. Эверетта, чтобы показать, что в пирахан цветообозначений нет: черный цвет в пирахан - цвет черной крови, красный обычный цвет крови, зеленый - цвет незрелости [13, с. 132; 7, с. 442]. К сожалению, А. Д. Кошелев не замечает, что эти описательные конструкции пирахан тоже являются цветобобзначениями, только привязанными к конкретным предметам того или иного цвета, которые в ходе филогенетической эволюции уступают место гораздо меньшему количеству обобщенных номинаций.

«Современный человек использует для называния различных цветовых оттенков множество опосредованных обозначений: аметистовый (amethyst), бронзовый (bronze), медный (copper), морковныий (carrot), каштановый (chestnut), шоколадный (chocolate), янтарный (amber)», - пишет А. Д. Кошелев [7, с. 446]. Однако именно эти обозначения являются не обобщенными, а конкретными, подобными описанным А. Р. Лурией. О том, что семантически эти обозначения идентичны цветовым описаниям пирахан, пишет и сам А. Д. Кошелев, но не считает их необобщенными. И важно признать, что приведенные Д. Л. Эвереттом и пересказанные А. Д. Кошелевым цветообозначения применяет далеко не каждый цивилизованный человек. Эти цветообозначения с разной степенью условности включаются в более обобщенные номинации, например шоколадный и каштановый в коричневый, янтарный в желтый, а некоторые их этих цветов может идентифицировать не каждый носитель русского языка, например аметистовый и, возможно, бронзовый. Хорошо известно, что до заимствования в русский язык слова оранжевый носители языка для обозначения соответствующего цвета вполне обходились номинацией красный, которой в английском (red) обозначают и рыжсий (фр. roux), и в целом, как известно, в германских и романских языках не различаются обозначения синего и голубого (ср. используемые для обозначения этих двух цветов англ. blue и фp. bleu).

Наконец, пора сказать и о тесно связанной с когницией биологической причине обобщений. В ходе когнитивной эволюции человек прибегает к обобщениям только потому, что его память оказывается перегруженной большим количеством различных частных номинаций, о чем писал еще И. М. Сеченов [11, с. 317]. Понятно, что чем больше видов деятельности - тем быстрее появляется потребность в обобщениях, но другие виды деятельности еще нужно воспринять, из чего следует, что новые виды деятельности приходят не сами по себе, а в результате эволюции такой когнитивной структуры, как восприятие, которое обеспечивает качество человеческой логики как строя мышления и может эволюционировать в диапазоне таких трех степеней, как: 1) правополушарное синкретичное восприятие, при котором познаваемые сущности выглядят цельными, не состоящими из частей и не имеющими признаков; 2) правополушарное, предпринимающее первую попытку категоризации поверхностное восприятие, при котором в познаваемом явлении выделяются лишь наиболее заметные части, а из его признаков выделяются тоже только самые заметные, категоризация по которым чаще всего бывает неверной; и, нормативное, 3) левополушарное альтернативное восприятие, при котором в познаваемом явлении выделяются все необходимые части и признаки, что обеспечивает корректность его категоризации (подробнее о степенях восприятия - см. в [10, с. 5105]). (А. Д. Кошелев предлагает свою схему степеней восприятия, согласиться с которой трудно. Так, автор пишет, что имеется «три уровня восприятия чая - синкретичный, на котором не разделяются вкусы заварки, сахара и воды; системный, когда они воспринимаются как самостоятельные компоненты; и системносистемный, когда во вкусе заварки различаются 
отдельные вкусовые оттенки» [7, с. 442]. Как можно убедиться, эта схема в целом соответствует традиционной теории развития, трактующей эволюцию как движение от синкретизма к дифференциации [12], поскольку в этой схеме второй и третий уровни являются результатом механистического представления двух различающихся лишь интенсивностью подуровней альтернативного (дифференцирующего) восприятия, резко противопоставленного восприятию синкретичному, но объясняющий переход от синкретизма к альтернативности уровень поверхностного восприятия в данной схеме отсутствует, что делает ее негармонично сбалансированной.) Корректная категоризация и есть спаянное с абстрактным мышлением обобщение по альтернативно воспринятым признакам.

Для выработки

цветообозначений важна абстрактностью мышления обобщению, небезразмерностью Альтернативное человеческой восприятие

обобщенных обеспечиваемая способность к мотивированная является эволюции восприятия, которая в свою очередь зависит от того, что можно назвать возможностями воспринимать альтернативы. Последние лучше воспринимаются на открытых пространствах: хорошо известны выводы антропологов о распадении 5 млн лет назад общего предка шимпанзе и человека на оставшихся жить в лесу шимпанзе и научившихся выживать в саванне австралопитеков, и не менее известно сегодня, что современные саванные шимпанзе оказываются разумнее своих лесных собратьев. Однако индейцы пирахан живут не на открытом пространстве, а в джунглях Амазонии, что уже ограничивает их возможности видеть альтернативы. То, что им дано природой воспринимать, - это лишь дикие животные, которых они убивают, плоды и травы, которые они собирают, и рыба, которую они ловят по очереди круглые сутки, ибо в разное время суток ловятся разные виды рыбы $[13$, с. $286 ; 7$, c. 447]. Животных, плоды, травы и виды рыб пирахан дифференцируют, но не обобщают так же хорошо, как чукчи - виды снега. Их долговременной и оперативной памяти на обозначение разных видов плодов, трав и рыбы вполне хватает, поэтому потребности в обобщениях они не испытывают.

Итак, мы доказали, что в пирахан отсутствуют не вообще цветобобзначения, а обобщенные цветобобзначения и что в пирахан нет обобщенных цветобобзначений не потому, что у носителей пирахан деятельность не требует различения цветов (цвета пирахан как раз различают - конкретнопредметно, как все первобытные этносы), а потому, что из-за природного ограничения возможности воспринимать альтернативы у пирахан нет потребности в обобщениях. Из этого следует, что, как мы и предположили в начале статьи, причиной фиксации в первобытных языках наличия обобщенных понятий при отсутствии их названий является такая разновидность логической ошибки подмены понятия, как некорректное перенесение современной цивилизованной ментальности на ментальность первобытного человека.

Таким образом, на примерах языков активного строя, в которых имеется только одна обобщенная оппозиция «живое - неживое», к которым принадлежит рассматриваемый в статье язык пирахан и в которых из-за преобладания синкретизма восприятия невозможно обобщение по более частным признакам, чем признаки живого и неживого, на примерах корреляций явлений языка пирахан с характеризующейся отсутствием прилагательных и обобщенных существительных речью полуторагодовалых, но не двухлетних цивилизованных детей, на примерах обобщенностинеобобщенности цветообозначений в цивилизованных и первобытных, в том числе пирахан, языках, с применением понятий объема памяти, степеней восприятия, логики как строя мышления и тесно связанной с обобщением абстрактности мышления можно считать доказанным, что постулируемое только для первобытных языков наличие родовых понятий при отсутствии их обозначений невозможно, а утверждение данного наличия является такой распространенной в настоящее время логической подменой понятия, как перенесение современной цивилизованной ментальности на ментальность первобытную.

\section{Литература}

1. Боас Ф. Введение к «Руководству по языкам американских индейцев» (Извлечения) // Звегинцев В. А. История языкознания XIX-XX веков в очерках и извлечениях. 3-е изд., доп. Ч. II. Москва: Просвещение, 1965. С. 170-180.

2. Гамкрелидзе Т. В., Иванов Вяч. Вс. Индоевропейский язык и индоевропейцы. Реконструкция и историкотипологический анализ праязыка и протокультуры. Кн. 1. Тбилиси: Изд-во Тбилисского ун-та, 1984. XCVI, 428 с.

3. Гвоздев А. Н. Формирование у ребенка грамматического строя русского языка. Часть вторая. Москва: Изд-во Академии педагогических наук РСФСР, 1949. 192 с.

4. Иванов Вяч. Вс. Чет и нечет: Асимметрия мозга и знаковых систем. Москва: Сов. радио, 1978. 184 с.: ил.

5. Климов А. Г. Очерк общей теории эргативности. М.: Наука, 1973. 264 с.

6. Климов А. Г. Типология языков активного строя. Москва: Наука, 1977. 320 с. 
7. Кошелев А. Д. Очерки эволюционно-синтетической теории языка / Сост. А. Д. Кошелев. Москва: Издательский Дом ЯСК, 2017. 528 с. (Разумное поведение и язык. Language and Reasoning.)

8. Лурия А.Р. Об историческом развитии познавательных процессов: Экспериментально-психологическое исследование. Москва: Наука, 1974. 172 с.

9. Мид М. Культура и мир детства. Избранные произведения. Пер. с англ. и коммент. Ю. А. Алексеева; Сост. и послесл. И. С. Кона. Москва: Главред. вост. лит-ры изд-ва «Наука», 1988. 429 с., ил.

10. Попов С. Л. Когнитивные основания эволюции форм русского синтаксического согласования: Монография. Харьков: НТМТ, 2013. 150 с.

11. Сеченов И. М. Элементы мысли // Сеченов И. М. Избранные произведения. Т. 1. Физиология и психология. Москва: Изд-во АН СССР, 1952. С. 272-426.

12. Чуприкова Н. И. Психология умственного развития: Принцип дифференциации. Москва: АО «Столетие», 1997. $480 \mathrm{c}$.

13. Эверетт Д. Л. Не спи - кругом змеи. Быт и язык индейцев амазонских джунглей. Москва: Издательский Дом ЯСК, 2016. $384 \mathrm{c}$.

\section{References}

1. Boas F. Vvedenie k «Rukovodstvu po yazykam amerikanskih indejcev» (Izvlecheniya) // Zvegincev V. A. Istoriya yazykoznaniya XIX-XX vekov v ocherkah i izvlecheniyah. 3-e izd., dop. CH. II. Moskva: Prosveshchenie, 1965. S. 170-180.

2. Gamkrelidze T. V., Ivanov Vyach. Vs. Indoevropejskij yazyk i indoevropejcy. Rekonstrukciya i istoriko-tipologicheskij analiz prayazyka i protokul'tury. Kn. 1. Tbilisi: Izd-vo Tbilisskogo un-ta, 1984. XCVI, $428 \mathrm{~s}$.

3. Gvozdev A. N. Formirovanie u rebenka grammaticheskogo stroya russkogo yazyka. CHast' vtoraya. Moskva: Izd-vo Akademii pedagogicheskih nauk RSFSR, 1949. $192 \mathrm{s.}$

4. Ivanov Vyach. Vs. CHet i nechet: Asimmetriya mozga i znakovyh sistem. Moskva: Sov. radio, 1978. 184 s.: il.

5. Klimov A. G. Ocherk obshchej teorii ergativnosti. M.: Nauka, 1973. 264 s.

6. Klimov A. G. Tipologiya yazykov aktivnogo stroya. Moskva: Nauka, 1977. $320 \mathrm{~s}$.

7. Koshelev A. D. Ocherki evolyucionno-sinteticheskoj teorii yazyka / Sost. A. D. Koshelev. Moskva: Izdatel'skij Dom YSK, 2017. 528 s. (Razumnoe povedenie i yazyk. Language and Reasoning.)

8. Luriya A. R. Ob istoricheskom razvitii poznavatel'nyh processov: Eksperimental'no-psihologicheskoe issledovanie. Moskva: Nauka, 1974. 172 s.

9. Mid M. Kul'tura i mir detstva. Izbrannye proizvedeniya. Per. s angl. i komment. Y. A. Alekseeva; Sost. i poslesl. I. S. Kona. Moskva: Glavred. vost. lit-ry izd-va «Nauka», 1988. 429 s., il.

10. Popov S. L. Kognitivnye osnovaniya evolyucii form russkogo sintaksicheskogo soglasovaniya: Monografiya. Har'kov: NTMT, 2013. $150 \mathrm{~s}$.

11. Sechenov I. M. Elementy mysli // Sechenov I. M. Izbrannye proizvedeniya. T. 1. Fiziologiya i psihologiya. Moskva: Izdvo AN SSSR, 1952. S. 272-426.

12. Chuprikova N. I. Psihologiya umstvennogo razvitiya: Princip differenciacii. Moskva: AO «Stoletie», 1997. 480 s.

13. Everett D. L. Ne spi - krugom zmei. Byt i yazyk indejcev amazonskih dzhunglej. Moskva: Izdatel'skij Dom YSK, 2016. $384 \mathrm{~s}$.

Попов Сергій Леонідович, доктор філологічних наук, професор кафедри російської мови, Університет імені Сунь Ятсена (135, вул. Синган Сі, Гуанчжоу, 510275, Китай); e-mail: s.leon.popov@gmail.com; https://orcid.org/0000-0002-3257-6245

Попов Сергей Леонидович, доктор филологических наук, профессор кафедры русского языка, Университет имени Сунь Ятсена (135, ул. Синган Си, Гуанчжоу, 510275, Китай); e-mail: s.leon.popov@gmail.com; https://orcid.org/0000-0002-3257-6245

Popov Sergei, Doctor of Philology, Professor of the Department of Russian Language Sun Yat-Sen University (135, Xingang Xi Road, Haizhu District, Guangzhou, 510275, China); email: s.leon.popov@gmail.com; https://orcid.org/0000-0002-3257-6245 